\title{
Equal Channel Angular Pressing of Tubular Samples
}

\author{
F. Djavanroodi ${ }^{1,2) \dagger}$, A.A. Zolfaghari ${ }^{3)}$, M. Ebrahimi ${ }^{3)}$ and K.M. Nikbin ${ }^{2)}$ \\ 1) Department of Mechanical Engineering, Imperial College, London, SW7, UK \\ 2) Department of Mechanical Engineering, Gassim University, Gassim, Saudi Arabia \\ 3) Department of Mechanical Engineering, Iran University of Science and Technology, Tehran, Iran \\ [Manuscript received 22 February 2013, in revised form 13 April 2013] \\ (C) The Chinese Society for Metals and Springer-Verlag Berlin Heidelberg
}

\begin{abstract}
A new technique to equal channel angular pressing of tubular samples has been proposed and investigated through experiments and simulations. Deformation behavior of copper tube sample was numerically analyzed during the first pass of tubular ECAP process. The investigation included the effect of various tube wall thicknesses on the effective strain magnitude and strain distribution uniformity. It is shown that tube wall thickness of $3.5 \mathrm{~mm}$ gives the optimum value for strain behavior. In addition, copper tube specimens with $3.5 \mathrm{~mm}$ wall thickness have been successfully ECAPed up to four passes with the die channel angle of $90^{\circ}$ using flexible polyurethane rubber pad. Micro-hardness measurements on both annealed and ECAPed tubes show that $33 \%$ and $57 \%$ increases in hardness value and also, $50 \%$ and $70 \%$ reductions in the grain size were achieved after the first and fourth passes respectively. Furthermore, tube wall thickness measurements show that the process does not change the dimension of deformed specimens.
\end{abstract}

\section{KEY WORDS: ECAP; Tube; FEM; Strain behavior; Hardness distribution}

\section{Introduction}

In recent years, severe plastic deformation (SPD) methods are used for fabricating bulk ultra-fine grained (UFG) metals and alloys ${ }^{[1-3]}$. These materials possess high mechanical properties at the ambient temperature and superior superplastic behavior at the elevated temperature ${ }^{[4,5]}$. In general, three categories entitling bulk ${ }^{[6-11]}$, sheet ${ }^{[12-14]}$ and tube ${ }^{[15-18]}$ classifications can be defined for the SPD techniques. Among various SPD techniques, ECAP process has obtained the most attention due to simplicity of die manufacturing and low cost. Hence, this process has been extensively developed including rotary-die ${ }^{[19]}$, multi-pass ${ }^{[20]}$, cross-ECAP ${ }^{[21]}$, sideextrusion ${ }^{[22]}$, cover tube casing $(\mathrm{CTC})^{[23]}$ and etc. On the other hand, it can be noted that fabricating UFG tube-shaped samples have been less pondered as compared to the other two groups. It may be related to the difficulties of techniques for tube-shaped samples recognized up to now.

† Corresponding author. Prof., Ph.D.; Tel.: +44 2075895111; E-mail address: f.djavanroodi@ic.ac.uk (F. Djavanroodi)

DOI: $10.1007 / \mathrm{s} 40195-013-0102-3$
The four well-known SPD methods for tubeshaped samples are spin extrusion $(\mathrm{SE})^{[15]}$, high pressure tube twisting $(\mathrm{HPTT})^{[16]}$, spin bonding $(\mathrm{SB})^{[17]}$ and tubular channel angular pressing (TCAP) ${ }^{[18]}$. In SE process developed by Neugebauer et al. ${ }^{[15]}$, the tube-shaped material is produced with a rotational forming under compressive circumstance as shown in Fig. 1(a) ${ }^{[15,24]}$. It is commonly used to fabricate axisymmetrically tube specimens from bulk billets. In HPPT process originated by Toth et al., the tube sample is placed inside a rigid disk as represented in Fig. 1(b) ${ }^{[16,25]}$. Then, a mandrel is located into the tube which is compressed with a compression machine in its elastic regime. It slightly expands in the radial direction due to the axial compression of the mandrel. The imposed strain in this process is not uniform in the thickness direction. Mohebbi and Akbarzadeh ${ }^{[26]}$ have developed a method based on cold bonding of cylinders by utilizing the tube spinning method; see Fig. 1(c). In this process, material is placed between the roller and mandrel and then, it gradually deforms to the final thickness. The common difficulty among these three SPD techniques for producing tube materials is theirs costs and complicated set-ups. Based on this conception, i.e. costs and simplicity of 
(a)

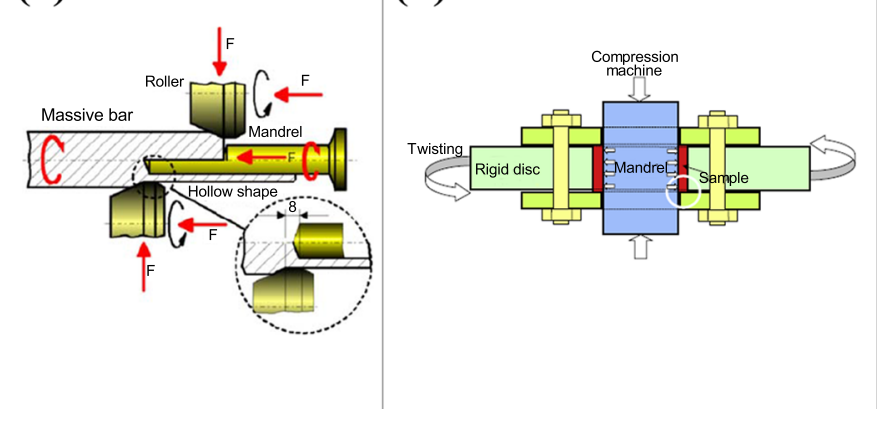

(c)

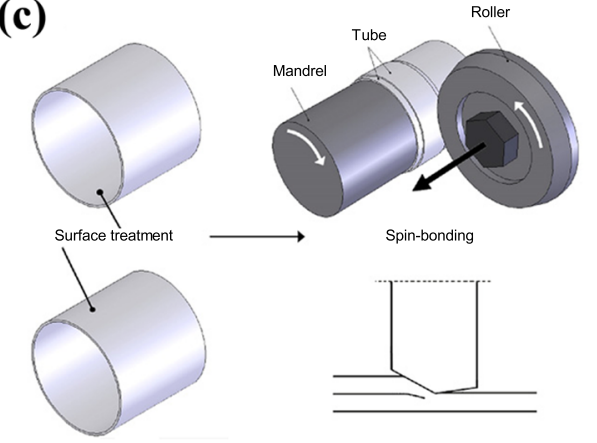

Fig. 1 Various severe plastic deformation methods to fabricate ultra-fine grain tube-shaped specimens: (a) spin extrusion; (b) high pressure tube twisting; (c) spin bonding

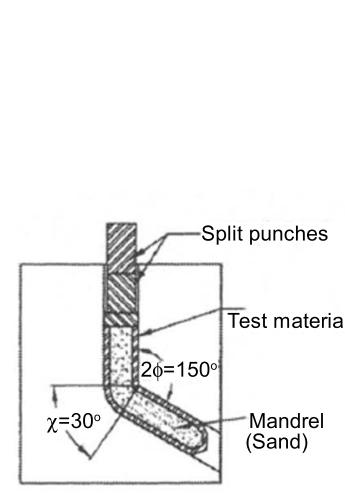

(a)

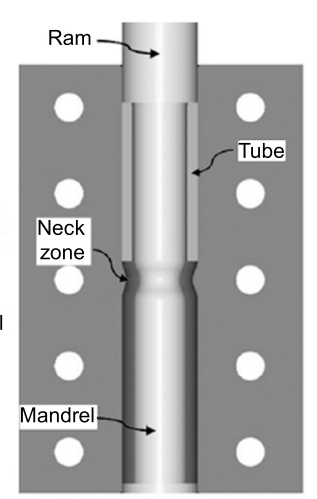

(b)
Fig. 2 Two methods for fabricating ultra-fine grain tubes using ECAP die: (a) conventional ECAP die; (b) tube channel angular pressing

set-ups, two new techniques have been acquainted. In both methods, tube sample is constructed using ECAP process. In the first one developed by Nagasekhar et al. ${ }^{[2]}$ and represented in Fig. 2(a), sand has been applied as the mandrel to maintain tubelarity of samples and then, the packing of tube sample with sand is pressed in the ECAP die. The required pressing load has the minimum magnitude as compared to the other techniques; because, friction between the sand and inner surface of tube aids the pressing of specimen. In the second one developed by Zangiabadi and Kazeminezhad ${ }^{[28]}$, the cylindrical shape work-piece is pressed in the tubular channel angular pressing. During one pass with this method, three shear events take place as shown in Fig. 2(b).

It is ideal to introduce a new method based on the simplicity of set-up and low cost to produce UFGed tube materials. In this research, potential of the conventional ECAP die to fabricate tube specimens with UFG structures has been investigated. Conventional ECAP die which is used for bulk UFG materials is been utilized to produce UFG tube samples. UFG tube of commercial pure copper has been produced for the first time with the conventional $90^{\circ} \mathrm{ECAP}$ die using polyurethane rubber as a mandrel. Since this is a new development of the ECAP process, scarce interrelated research is reported. In the numerical section, effective strain magnitude and strain distribution uniformity for various tube wall thicknesses have been analyzed utilizing 3D-FEM and the optimum tube wall thickness has been obtained based on the appropriate effective strain and the best strain distribution homogeneity. In the experimental part, tube specimens have been ECAPed using polyurethane rubber pad up to four passes by route $\mathrm{C}$ (i.e. sample is rotated $180^{\circ}$ about longitudinal axis after each consecutive passes). Furthermore, the hardness behavior of unECAPed (annealed) and also, first and fourth passes of pressed specimens has been investigated by recording micro-hardness test in transverse plane, longitudinal and thickness directions. Finally, tube wall thickness variation and microstructure observation of annealed and ECAPed samples have been obtained and discussed.

\section{Numerical Procedure}

The commercial finite element code, ABAQUS/Standard6.10.1 software, was employed to investigate strain behavior of pure copper tubeECAPed specimen after first pass. Both die and punch were assumed to be discrete rigid (no deformation). The constant punch rate was equal to the $1.5 \mathrm{~mm} / \mathrm{s}$ similar to the experimental work and also, friction coefficient was taken to be $0.1^{[23]}$. Coulomb friction was used for simulation. A hyper-elastic and elasto-plastic models were applied to describe polyurethane rubber pad and tube specimen, respectively. The behavior of the non-linear hyper-elastic and incompressible rubber-like material is usually described by the Mooney-Rivlin model, which uses a strain energy function $\mathrm{W}$. The derivative of $\mathrm{W}$ with respect to a strain component determines the corresponding stress component. The strain energy can be expressed by the following function ${ }^{[29]}$ :

$$
\sigma_{i j}=\frac{\partial W}{\partial \varepsilon_{i j}}
$$


Table 1 Mechanical properties of the polyurethane pad ${ }^{[29]}$

\begin{tabular}{cccc}
\hline Hardness shore A & M-R constant $C_{01}(\mathrm{MPa})$ & M-R constant $C_{10}(\mathrm{MPa})$ & Poisson's ratio \\
\hline 90 & 0.969 & 0.393 & 0.4999 \\
\hline
\end{tabular}

(a)

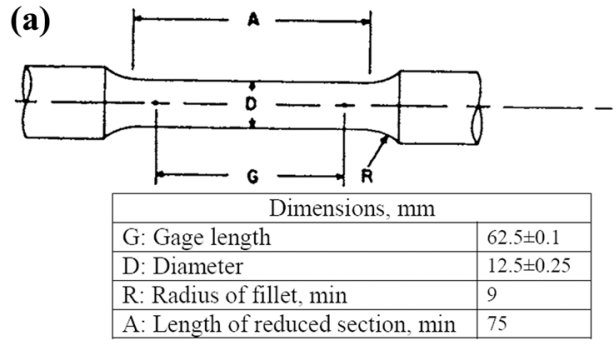

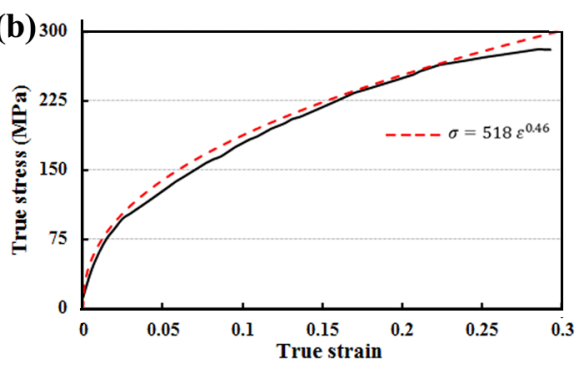

Fig. 3 Specimen dimensions (a) and true stress-true strain curve (b) of $\mathrm{Cu}$ obtained by tensile test with curve fitting of Hollomon model

$$
W=\sum_{k+m=1}^{n} C_{k m}\left(I_{1}-3\right)^{k}+\left(I_{2}-3\right)^{m}+\frac{D}{2}\left(I_{3}-1\right)^{2}
$$

where $I_{1}, I_{2}$ and $I_{3}$ are the strain invariants, $D$ is the bulk modulus and $C_{k m}$ is the constant of the MooneyRivlin material model. For incompressible materials, $I_{3}=1$ and $n=1$. The mechanical properties of the rubber pad, obtained from compression test according to ASTM D575 are listed in Table $1^{[29]}$.

Fig. 3 shows tensile specimen and also, true stresstrue strain curve of annealed pure copper. In addition, plastic deformation behavior of material is described using Hollomon's equation:

$$
\sigma=K \varepsilon^{n}
$$

where $\sigma, \varepsilon, K$ and $n$ are effective von Mises stress, effective plastic strain, strength coefficient and strain hardening exponent, respectively. The magnitude of the strength coefficient $(K=518 \mathrm{MPa})$ strain hardening exponent $(n=0.46)$ obtained by tensile test according to ASTM B 557M (2010).

Since the model was symmetrical about the middle plane of the ECAP, half of the sample die, rubber pad and punch were analyzed and the symmetrical boundary conditions were applied. Adaptive meshing, mass scaling and automatic re-meshing were applied and justified for all of the simulations to prevent failure of the mesh during large deformation and to reduce computation time. By considering the tube dimension $(\Phi=19 \mathrm{~mm}, t=3.5 \mathrm{~mm}$ and $L=140 \mathrm{~mm}$ ), two different element sizes were applied for the longitudinal and thickness directions. Various element size and element number were respectively utilized for the longitudinal and thickness directions, simultaneously to improve the accuracy of the model. Mesh sensitivity was performed and the optimum element size was found to be $2 \mathrm{~mm}$ at the longitudinal direction. In addition, 30 elements were employed at the thickness direction. So, the mesh number for half of the

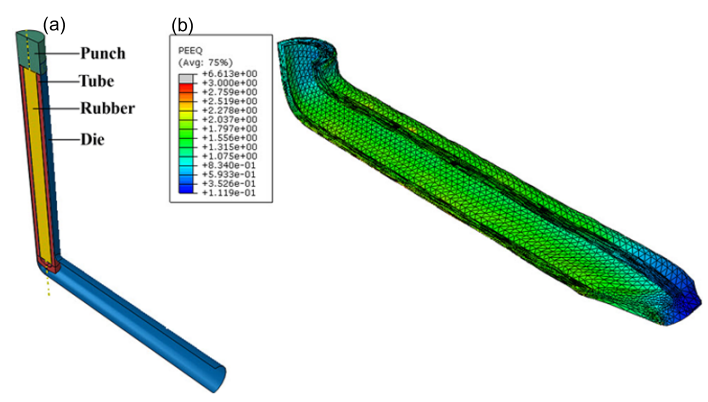

Fig. 4 ECAP die set-up (a) and half of the deformed tube $(t=3.5 \mathrm{~mm})(\mathrm{b})$ after first pass

copper tube specimen depended on the thickness values altering from 27500 to 35500 .

After FEM validation using pressing force obtained by experimental work, the tube with the wall thicknesses of $1 \mathrm{~mm}, 1.5 \mathrm{~mm}, 2 \mathrm{~mm}, 2.5 \mathrm{~mm}, 3 \mathrm{~mm}$, $3.5 \mathrm{~mm}$ and $4 \mathrm{~mm}$ have been analyzed to investigate effective strain magnitude and strain distribution uniformity in the ECAPed tube. The aim is to obtain optimum copper tube wall thickness with suitable effective strain magnitude and strain distribution uniformity. Fig. 4 displays the ECAP die set-up and strain contour of ECAPed tube (the wall thickness of $3.5 \mathrm{~mm}$ ) after first pass.

\section{Experimental}

Extruded commercial pure copper in the shape of tube (outer diameter of $19 \mathrm{~mm}$ and $3.5 \mathrm{~mm}$ in thickness) was prepared and then, cut into $140 \mathrm{~mm}$ long pieces. Before operation, the $\mathrm{Cu}$ tube was annealed at the $500{ }^{\circ} \mathrm{C}$ for $1 \mathrm{~h}$ and slowly cooled at the furnace. Flexible polyurethane rubber with a shore A (HD90) was fitted as a mandrel inside the $\mathrm{Cu}$ sample before pressing. The ECAP die with the die channel angle of $90^{\circ}$, outer corner angle of $15^{\circ}$ and channel diameter of $19.2 \mathrm{~mm}$ was designed and manufactured. The die set-up and also, specimens before and after ECAP 


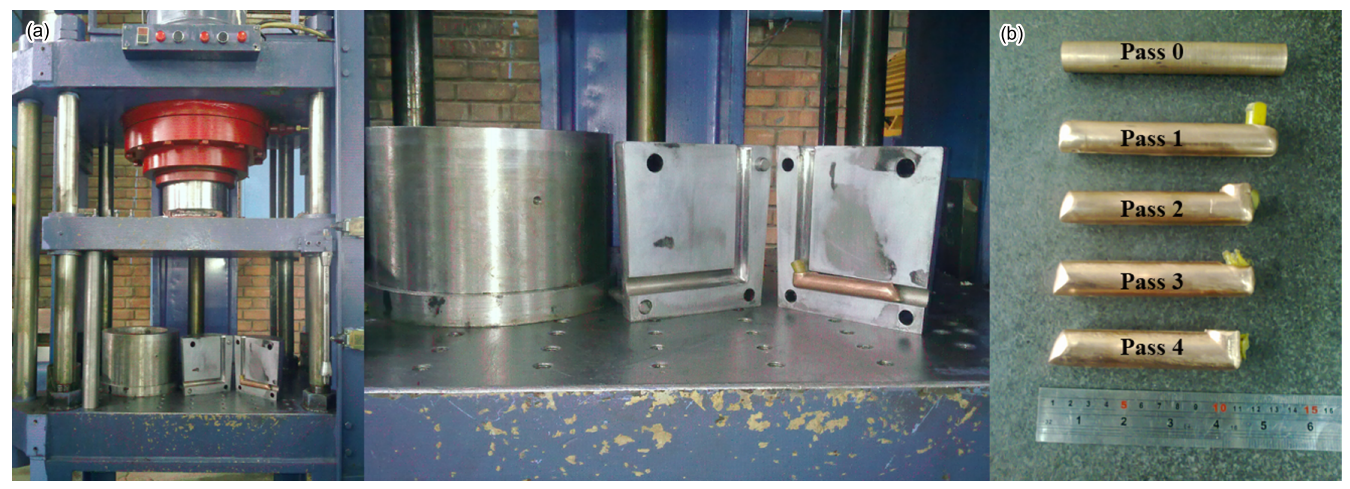

Fig. 5 ECAP die set-up (a) and copper samples (b) before and after ECAP process up to four passes

process up to four passes are shown in Fig. 5. Molybdenum disulfide $\left(\mathrm{MoS}_{2}\right)$ with the coefficient of friction of 0.1 was used as a lubricant to reduce frictional effects between outer surfaces of tube and $\mathrm{die}^{[23]}$. ECAP process was carried out at room temperature using hydraulic press with a ram speed of $1.5 \mathrm{~mm} / \mathrm{s}$.

For copper tube specimens in un-ECAPed (annealed) and ECAPed conditions, a total numbers of 242 micro-hardness tests (a load of $0.49 \mathrm{~N}$ for a dwell time of $15 \mathrm{~s}$ ) in the transverse plane, longitudinal and thickness directions have been recorded. Also, microstructure evaluation using optical microscopy (OM) has been employed to confirm the grain refinement of ECAPed tube. Furthermore, tube wall thickness variation before and after ECAP process have been measured at different locations and compared.

\section{Results and Discussion}

\subsection{Numerical results}

\subsubsection{Verification of FEM}

Three dimensional finite element analyses (3DFEA) have been employed to investigate strain behavior of the ECAPed tube after $1^{\text {st }}$ pass pressing. The pressing force is an important parameter in metal forming. To verify FEA results, simulated load-stroke curve and peak load calculations were compared with the experimentally recorded load-stroke curve and peak load. For the tube of commercial pure copper with the $t=3.5 \mathrm{~mm}$ after first pass pressing, the peak load acquired from the experimental and the numerical works were $254 \mathrm{kN}$ and $236 \mathrm{kN}$, respectively (see Fig. 6). This represents about $7 \%$ discrepancy between the experimental and numerical outcomes which is acceptable for all engineering purposes. In over all, good conformity is observed between the FEM calculations and experimental results.

\subsubsection{Strain behavior}

After confirming the validity of FE modeling, various tube wall thicknesses $(1 \mathrm{~mm}, 1.5 \mathrm{~mm}, 2 \mathrm{~mm}$, $2.5 \mathrm{~mm}, 3 \mathrm{~mm}, 3.5 \mathrm{~mm}$ and $4 \mathrm{~mm}$ ) have been sim-

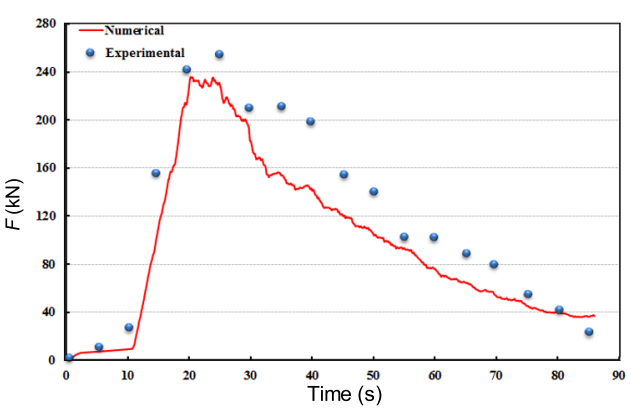

Fig. 6 Comparison of experimental and numerical ECAP forces for first pass $\mathrm{Cu}$ tube $(t=3.5 \mathrm{~mm})$

ulated to investigate effective strain magnitude and strain distribution uniformity as shown in Fig. 7. Furthermore, the head and tail zone effect on effective strain magnitude and strain distribution uniformity was also considered. Based on these data, the optimum wall thickness of ECAPed tube was obtained by considering the appropriate effective strain value and the best strain dispersal uniformity.

To investigate how hardness dispersal or strain distribution spreads, standard deviation (SD) as a statistical parameter was applied as follows ${ }^{[23,30]}$ :

$$
S D=\sqrt{\frac{\sum_{i=1}^{n}\left(x_{i}-M\right)^{2}}{n-1}}
$$

where $X_{i}, M$ and $n$ are the individual score, mean of all scores and number of scores, respectively. In general, less value for SD leads to better hardness or strain distribution uniformity. Fig. 8 show the effective strain (ES) and standard deviation (SD) values in the sample and in the specimen excluding head and tail zone for the first pass ECAP.

Since the strain distribution heterogeneity and least effective strain magnitude tends to happen at the head and tail parts of ECAPed samples therefore, it is anticipated that high effective strain value with the best strain dispersal homogeneity can be achieved irrespective of head and tail parts; see Fig. 8. Also, it is observed that increasing tube wall thickness to $4 \mathrm{~mm}$ from $1 \mathrm{~mm}$ leads to higher magnitude of effec- 


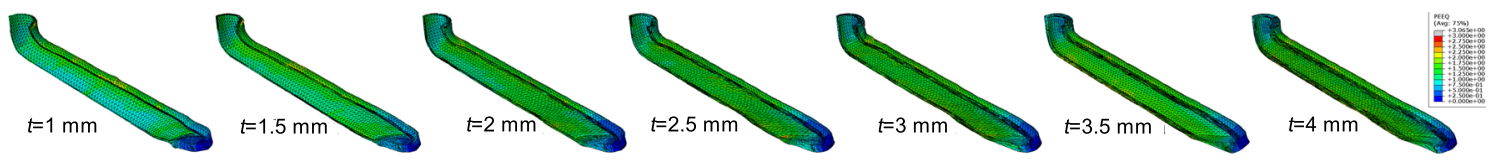

Fig. 7 3D strain contour for various wall thickness tubes after first pass of ECAP process
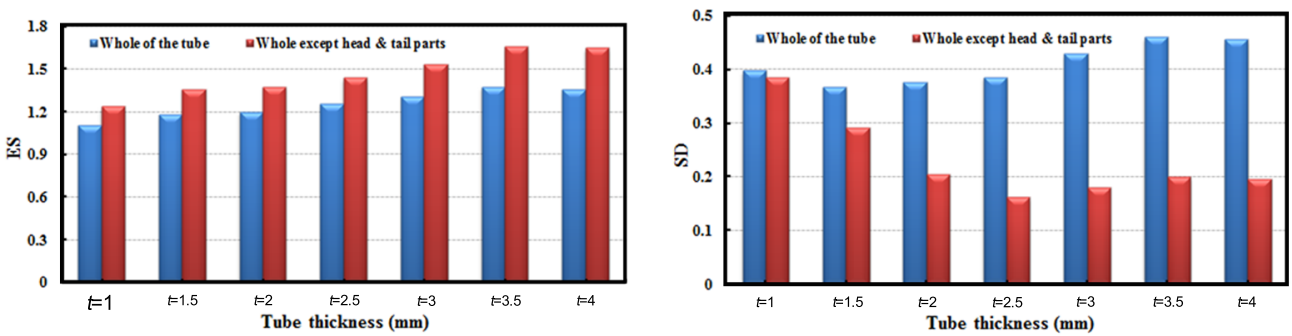

Fig. 8 Magnitudes of effective strain (ES) and standard deviation (SD) for various tube wall thicknesses on both tube and the sample excluding head and tail zone after the first pass ECAP process

Table 2 Percentage difference in the effective strain (ES) and standard deviation (SD) values for various first pass ECAPed tube wall thicknesses as compared to $t=3.5 \mathrm{~mm}$

\begin{tabular}{ccccccc}
\hline & $t=1 \mathrm{~mm}$ & $t=1.5 \mathrm{~mm}$ & $t=2 \mathrm{~mm}$ & $t=2.5 \mathrm{~mm}$ & $t=3 \mathrm{~mm}$ & $t=4 \mathrm{~mm}$ \\
\hline $\mathrm{ES}$ & $-25 \%$ & $-18 \%$ & $-17 \%$ & $-13 \%$ & $-7 \%$ & 0 \\
$\mathrm{SD}$ & $-93 \%$ & $-45 \%$ & $-2.5 \%$ & $19 \%$ & $9 \%$ & $2 \%$ \\
\hline
\end{tabular}

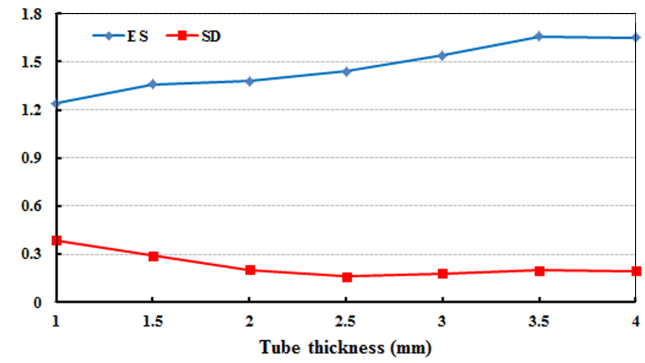

Fig. 9 Magnitudes of effective strain (ES) and standard deviation (SD) for the various tube wall thicknesses after first pass of ECAP process

tive strain. This increasing slop is saturated when the tube wall thickness reaches about $3.5 \mathrm{~mm}$. On the other hand, there is an optimum value for the SD magnitude around $t=2.5 \mathrm{~mm}$ as shown in Fig. 9 .

Table 2 represents the percentage difference in the effective strain and standard deviation magnitudes when various tube wall thicknesses are compared to the $t=3.5 \mathrm{~mm}$. As can be observed, next to the $t=3.5 \mathrm{~mm}$, the tube wall thickness of $4 \mathrm{~mm}$ is the suitable candidate for optimum wall thickness. In the other word, there is negligible difference in the effective strain and SD values for both $t=3.5 \mathrm{~mm}$ and $t=4 \mathrm{~mm}$.

\subsection{Experimental results}

\subsubsection{First pass ECAP}

Fig. 10 shows the positions of Vickers hardness (HV) tests for the first pass ECAPed tube. The ECAPed specimen was sliced in to 6 separate pieces (Fig. 10(a)) and the head and the tail segments were

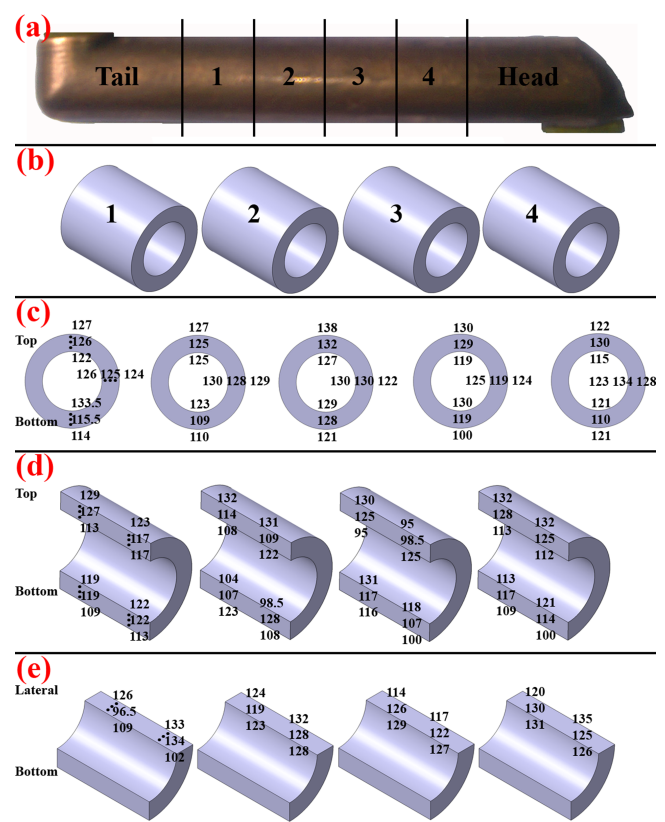

Fig. 10 Locations and magnitude of Vickers microhardness (HV) measurements for the first pass ECAPed $\mathrm{Cu}$ tube

removed. So, 4 small samples equal in length (18 $\mathrm{mm}$ ) were selected for hardness behavior examination; see Fig. 10(b). Hardness tests were performed at the various locations of these 4 samples as shown in Fig. 10(c), Fig. 10(d) and Fig. 10(e)). In total, 117 micro-hardness tests have been recorded for the first ECAPed tube. Also for the un-ECAPed tube (annealed copper), the magnitude of $\mathrm{HV}$ was obtained by averaging hardness measurements at 8 different 
Table 3 Vickers hardness magnitudes and SD for $3.5 \mathrm{~mm}$ wall thickness $\mathrm{Cu}$ tube before ECAP and after the first pass ECAP

\begin{tabular}{|c|c|c|c|c|c|c|c|}
\hline & \multirow{2}{*}{$\begin{array}{l}\text { Initial } \\
\text { Whole }\end{array}$} & \multicolumn{6}{|c|}{ After first pass ECAP } \\
\hline & & Top & Lateral & Bottom & Outer & Middle & Inner \\
\hline Hardness (HV) & 91 & 121.7 & 124.4 & 115.9 & 121 & 120.9 & 120.1 \\
\hline Standard deviation (SD) & 4.8 & 10.3 & 8.1 & 9.1 & 10.8 & 9.3 & 9.5 \\
\hline
\end{tabular}

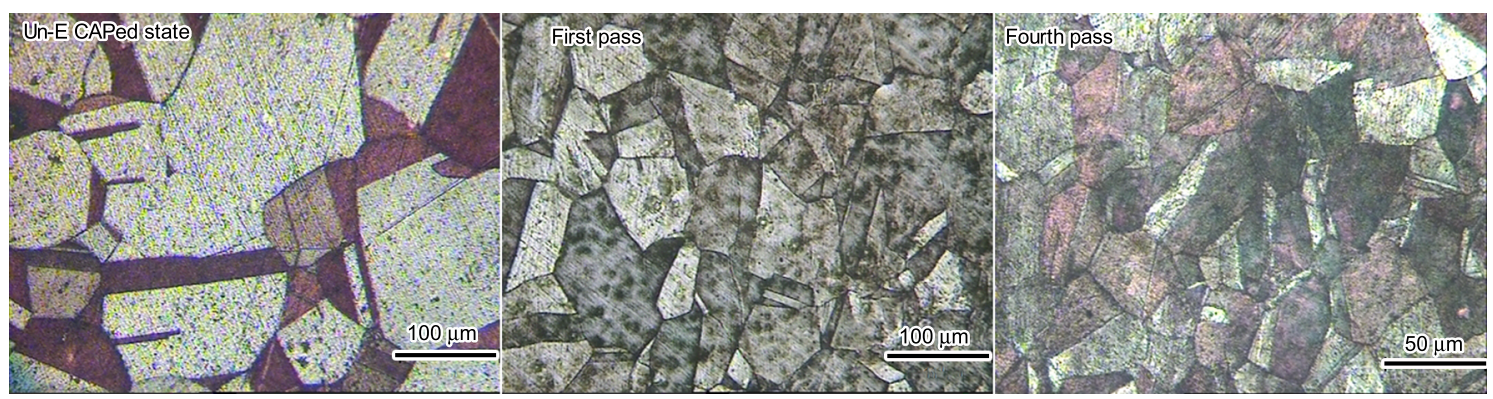

Fig. 11 Microstructure of pure copper before and after first and fourth passes of ECAP process

locations. These measurements were utilized to investigate hardness distribution at the outer, middle and inner surfaces and also, top, lateral and bottom parts of deformed tube.

The magnitudes of average hardness and SD at the top, lateral and bottom zones and also, outer, middle and inner surfaces of the first pass ECAPed-tube $(t=3.5 \mathrm{~mm})$ are separately obtained and represented in Table 3. As can be seen, the minimum hardness value in the sample belongs to the bottom region of the tube, where a combination of shear and bending stress is present due to non-zero value of outer die corner angle. On the other hand, the highest magnitude of hardness at the cross-section of deformed sample is $124.4 \mathrm{HV}$, related to the lateral region of the ECAPed tube. There are approximately $7 \%$ and $3 \%$ enhancements in the hardness value for the lateral area as compared to the bottom and top regions of first pass, respectively. Also, the lateral region of the ECAPed specimen has less SD value indicating that there is more hardness distribution uniformity in this zone. So, it can be said from the transverse and longitudinal directions point of view that lateral region of ECAPed copper tube has the highest hardness magnitude with the best hardness distribution homogeneity.

Furthermore, Table 3 indicates that there is not considerable difference between the hardness magnitudes of outer, middle and inner surfaces of the first pass ECAPed sample. The $15 \%$ value for the nonuniformity of hardness in the outer surface compared with middle and inner surface maybe relates to the friction effect between this surface and the die. So, the outer surface of the ECAPed sample has the worst hardness dispersal uniformity from the thickness direction point of view.

As a summary of this part, the overall magnitudes of hardness and SD are $120.7 \mathrm{HV}$ and 9.5 after the first pass ECAP, respectively. For the annealed state, the values are: hardness is $91 \mathrm{HV}$ and $\mathrm{SD}$ is 4.8. This indicates that ECAPed of tube after single pass increases the hardness value by $33 \%$ and also, this enhancement in the hardness behavior is be accompanied with the material strength and refining of the grains. Although ECAP operation of $\mathrm{Cu}$ sample leads to the mounting of the strength, there is about $98 \%$ increase in the $\mathrm{SD}$ value after first pass; indicating that this process induces non-uniformity in the hardness behavior for the deformed condition as compared to annealed state after the first pass ECAP.

\subsubsection{Four passes ECAP}

To investigate the hardness, microstructure and wall thickness variation at the higher passes of pressing, copper tube specimen has been ECAPed up to four by route $\mathrm{C}$. The results show that hardness magnitude of copper tubular ECAPed sample is $143 \mathrm{HV}$ with the standard deviation of 8.1. This indicates that fourth pass ECAP of copper tube work-piece causes an increase of hardness value to $18 \%$ and $57 \%$ as compared to the first pass and annealed condition. Also, the results indicate that the uniformity of hardness distribution increases by about $15 \%$ as compared with the first pass. So, ECAPing of tube sample to higher passes leads to higher hardness magnitude with better hardness distribution.

As known, ECAP process enhances significantly mechanical properties utilizing grain size refinement of metals and alloys ${ }^{[1,31]}$. To verify the refining of the $\mathrm{Cu}$ ECAPed tube after $1^{\text {st }}$ and $4^{\text {th }}$ pass pressings, optical microscopy (OM) observations for initial and ECAPed states have been compared; see Fig. 11. As can be seen, average grain size magnitudes of specimen for initial and also, after first and fourth pass pressings are $80 \mu \mathrm{m}, 40 \mu \mathrm{m}$ and $25 \mu \mathrm{m}$, respectively according to ASTM E112. These indicate that one 
and four passes of ECAP process lead to $50 \%$ and $70 \%$ reductions at the grain size.

Tube wall thickness variation before and also, after first and fourth passes of pressing were measured at 30 different locations and compared. The results showed that for all conditions, the wall thickness variation was about $(3.5 \pm 0.16) \mathrm{mm}$; indicating that the process did not change the tube dimension.

\section{Conclusions}

Equal channel angular pressing die with the $\Phi=90^{\circ}, \Psi=15^{\circ}$ and $d=19.2 \mathrm{~mm}$ has been designed and manufactured. Commercial pure copper in the shape of tubular samples with the wall thickness of $3.5 \mathrm{~mm}$ has been successfully ECAPed up to four passes by route $\mathrm{C}$ using polyurethane rubber pad. The magnitudes of hardness at the different locations of both un-ECAPed and ECAPed tubes after first and fourth passes were obtained and compared using micro-hardness tests. In addition, influences of various tube wall thicknesses on the effective strain magnitude and strain distribution uniformity have been numerically analyzed for the first pass of tubular ECAP process. The following conclusions can be drawn:

(1) The FEM results on the first pass of ECAP process indicated that increasing tube wall thickness results in higher effective strain magnitude and better strain distribution uniformity.

(2) The first pass ECAP process increases the mean hardness magnitude from $91 \mathrm{HV}$ to $121 \mathrm{HV}$. The lateral zone of the tube has higher magnitude of hardness $(3 \%$ and $7 \%)$ and better hardness distribution uniformity $(21 \%$ and $11 \%$ ) as compared to the top and bottom zones. Also, middle and inner surface has better hardness uniformity (about 15\%) as compared to outer surface of the tube. Furthermore, there is not considerable difference between the HV magnitudes of inner, middle and outer surfaces of the ECAPed copper tube.

(3) The hardness magnitudes and its standard divations of ECAPed copper are $(121 \mathrm{HV}, 9.5)$ and (143 HV, 8.1) after one and four passes by route $\mathrm{C}$ as compared to the annealed state $(91 \mathrm{HV}, 4.8)$, respectively. This indicates that additional ECAP passes leads to higher hardness magnitude with better hardness distribution homogeneity.

(4) Copper tube grain size measurement indicated that one and four passes of ECAP process reduce the grain size by about $50 \%$ and $70 \%$, respectively.

(5) Tube wall thickness variation measurement showed that ECAP process does not change the tube dimension.

\section{REFERENCES}

[1] R.Z. Valiev and T.G. Langdon, Prog. Mater. Sci. 51
(2006) 881

[2] M. Furukawa, Y. Iwahashi, Z. Horita, M. Nemoto and T.G. Langdon, Mater. Sci. Eng. A 257 (1998) 328.

[3] T. Aida, K. Matsuki, Z. Horita and T.G. Langdon, Scr. Mater. 44 (2001) 575.

[4] A.V. Sergueeva, V.V. Stolyarov, R.Z. Valiev and A.K. Mukherjeeb, Scr. Mater. 43 (2000) 819.

[5] R. Mahmudi, R. Alizadeh and A.R. Geranmayeh, Scr. Mater. 64 (2011) 521.

[6] W.J. Kim, C.W. An, Y.S. Kim and S.I. Hong, Scr. Mater. 47 (2002) 39.

[7] A.P. Zhilyaev and T.G. Langdon, Prog. Mater. Sci. 53 (2008) 893.

[8] Y. Beygelzimer, V. Varyukhin, S. Synkov and D. Orlov, Mater. Sci. Eng. A 503 (2009) 14.

[9] S.M. Fatemi-Varzaneh and A. Zarei-Hanzaki, Mater. Sci. Eng. A 504 (2009) 104.

[10] S. Biswas and S. Suwas, Scr. Mater. 66 (2012) 89.

[11] Y.J. Chen, Q.D. Wang, H.J. Roven, M.P. Liu, M. Karlsen, Y.D. Yu and J. Hjelen, Scr. Mater. 58 (2008) 311.

[12] J.C. Lee, H.K. Seok and J.Y. Suh, Acta Mater. 50 (2002) 4005.

[13] Y. Saito, N. Tsuji, H. Utsunomiya, T. Sakai and R.G. Hong, Scr. Mater. 39 (1998) 1221.

[14] D.H. Shin, J.J. Park, Y.S. Kim and K.T. Park, Mater. Sci. Eng. A 328 (2002) 98.

[15] R. Neugebauer, R. Glass, M. Kolbe and M. Hoffmann, J. Mater. Process. Technol. 125-126 (2002) 856.

[16] A. Pougis, L.S. Tóth, O. Bouaziz, J.J. Fundenberger, D. Barbier and R. Arruffat, Scr. Mater. 66 (2012) 773.

[17] M.S. Mohebbi and A. Akbarzadeh, Mater. Sci. Eng. A 528 (2010) 180.

[18] G. Faraji, M.M. Mashhadi and H.S. Kim, Mater. Lett. 65 (2011) 3009.

[19] A. Ma, Y. Nishida, K. Suzuki, I. Shigematsu and N. Saito, Scr. Mater. 52 (2005) 433.

[20] G. Purcek, O. Saray, O. Kul, I. Karaman, G.G. Yapici, M. Haouaoui and H.J. Maier, Mater. Sci. Eng. A $\mathbf{5 1 7}$ (2009) 97.

[21] A.V. Nagasekhar and H.S. Kim, Computational Mater. Sci. 43 (2008) 1069.

[22] A. Azushima and K. Aoki, Mater. Sci. Eng. A 337 (2002) 45 .

[23] F. Djavanroodi, M. Daneshtalab and M. Ebrahimi, Mater. Sci. Eng. A 535 (2012) 115.

[24] R. Neugebauer, R. Glass and M. Hoffmann, CIRP Ann.-Manuf. Technol. 54 (2005) 241.

[25] L.S. Tóth, M. Arzaghi, J.J. Fundenberger, B. Beausir, O. Bouaziz and R. Arruffat-Massion, Scr. Mater. 60 (2009) 175.

[26] M.S. Mohebbi and A. Akbarzadeh, J. Mater. Process. Technol. 210 (2010) 510.

[27] A.V. Nagasekhar, U. Chakkingal and P. Venugopal, J. Mater. Process. Technol. 173 (2006) 53.

[28] A. Zangiabadi and M. Kazeminezhad, Mater. Sci. Eng. A 528 (2011) 5066.

[29] M. Borhani and F. Djavanroodi, Mater. Sci. Eng. A 546 (2012) 1.

[30] V.P. Basavaraj, U. Chakkingal and T.S.P. Kumar, J. Mater. Process. Technol. 209 (2009) 89.

[31] Q. Xue, I.J. Beyerlein, D.J. Alexander and G.T. Gray III, Acta Mater. 55 (2007) 655. 